\title{
INFLUENCE OF THE HRV TIME SERIES LENGTH ON THE PREDICTIVE ABILITY FOR ADVERSE CLINICAL EVENTS
}

\author{
Laurita dos Santos*, Joaquim J. Barroso ${ }^{\dagger}$, Elbert E. N. Macau ${ }^{\ddagger}$, Moacir F. De Godoy ${ }^{\S}$ \\ * Laboratório Associado de Computação e Matemática Aplicada - INPE \\ CETEC Educacional S/A - ETEP Faculdade - Taubaté, \\ São Paulo, Brasil \\ ${ }^{\dagger}$ Laboratório Associado de Plasma \\ Instituto Nacional de Pesquisas Espaciais - INPE \\ São José dos Campos, São Paulo, Brasil \\ ${ }^{\ddagger}$ Laboratório Associado de Computação e Matemática Aplicada \\ Instituto Nacional de Pesquisas Espaciais - INPE \\ São José dos Campos, São Paulo, Brasil \\ $\S$ Núcleo Transdisciplinar de Estudos de Complexidade e Caos (NUTECC) \\ Faculdade de Medicina de São José do Rio Preto \\ São José do Rio Preto, São Paulo, Brasil
}

Emails: lauritas9@gmail.com, barroso@plasma.inpe.br, elbert@lac.inpe.br, mf60204@gmail.com

\begin{abstract}
Heart Rate Variability has been reported as very simple and adequate methodology to evaluate the homeostasis of an individual. It can easily be measured by recording the RR interval from a heart generated signal, which can be performed by a noninvasive procedure with, for example, Holter or Polar cardiac monitors. The aim of the present study was to verify the influence of the temporal series length on the predictive ability for adverse events using the heart rate variability. Results indicated that series with $1,000 \mathrm{RR}$ intervals retain the same capacity of the clinic interpretation of series up to 3,000 RR intervals. The predictive power was assessed by ROC curve analysis, and no significant statistical differences were found among the short and long series analyzed.
\end{abstract}

Keywords - Time series length, Poincaré plot, ROC curve analysis, Heart Rate Variability.

Resumo - A variabilidade da frequência cardíaca (VFC) tem sido apontada como uma metodologia simples e adequada para avaliar a homeostase de um indivíduo. A VFC pode ser facilmente medida obtendo-se os intervalos RR do sinal gerado do coração, a partir de monitores cardíacos como o Polar e/ou Holter. O principal objetivo desse estudo foi verificar a influência do tamanho das séries temporais com habilidade de predizer a ocorrência de eventos adversos usando a variabilidade da frequência cardíaca. Os resultados indicam que as séries temporais com 1.000 intervalos RR mantêm a mesma capacidade de interpretação clínica de séries até 3.000 intervalos RR. A capacidade de predição foi avaliada pela curva ROC, e diferenças estatísticas não significativas foram encontradas para as séries curtas e longas analisadas.

Keywords - Gráfico de Poincaré, Análise da curva ROC, Tamanho das séries temporais, Variabilidade da Frequência Cardíaca.

\section{Introduction}

Cardiac measuring devices, either Holter (Krum et al., 1995; Goldsmith et al., 1997) or Polar monitors (Gamelin et al., 2006; Vanderlei et al., 2008) produce time series of RR intervals that, while reflecting heartbeats, allow analysis of alterations in the homeostasis of an individual (Vanderlei et al., 2009). Depending on acquisition time and specific conditions of the individual, time series of the RR intervals or tachograms may have different extensions. In general, it is expected that the analysis of tachograms with longer extension provide more information, regardless of the difficulty in collecting the RR signal. Therefore, it is important to establish the minimum extension of the time series to statistically represent the counterpart series with longer extension.

\section{Data}

The RR intervals series were collected using the Polar® monitor (S810i or RS 800) (Gamelin et al., 2006; Vanderlei et al., 2008; Nunan et al., 2009; Selig et al., 2011). For this analysis, the variables $S D 1, S D 2$ and $S D 1 / S D 2$ were selected (see Section 3$)$.

To evaluate the influence of the extension of the time series on the prediction of clinical events, a group of 42 time series from adults with coronary artery disease in the preoperative period of surgical myocardial revascularizationin was chosen, because it was known from this group that thirty seven individuals had a good outcome and five died in hospital after surgery. This allowed us to compare the predictive power of the variables of the Poincaré plot according to time series size (1,000 and 2,000 and longer than 2,000 RR inter- 
vals initially recorded). The objective was to find the shortest time series statistically representative out of the total time series that maintainined the ability to predict the occurrence of a clinically relevant event, in this case death.

\section{Poincaré Plot}

The Poincaré plot is defined as a method of analysis based on linear and nonlinear dynamics, whereby each value (an RR interval) of the analyzed series is plotted against the previous value.

This method have been used in studies of heart rate variability (HRV) (Brennan et al., 2001; Piskorski and Guzik, 2007; Karmakar et al., 2009; Vanderlei et al., 2009), considered an important method with features to enable analysis by visual inspection summarizing a series of $\mathrm{RR}$ intervals in a figure. Moreover, the Poincaré plot is also a technique that provides quantitative information about the behavior of short-HRV $(S D 1)$ and long (SD2) durations (Piskorski and Guzik, 2007).

According to Piskorski and Guzik (2007) the Poincaré plot of RR intervals is composed of points $\left(R R_{i}, R R_{i+1}\right)$, where a pair of consecutive $R R$ intervals specifies a coordinate point in the graph (see Figure 1). Among other measures, from the graph the following parameters can be extracted: $X 1, X 2$, centroid, $S D 1, S D 2$ and $S D 1 / S D 2$. Figure 1 shows a sample chart with the Poincaré parameters mentioned above.

The Poincaré plot parameters used in this work are directly related to the physiology of the heart and to the autonomic nervous system. The parameter $S D 1$ relates to the short range of $\mathrm{RR}$ intervals, reflecting the variability of successive intervals, connected to the parasympathetic control of sinus node, whilst $S D 2$ relates to long range $\mathrm{RR}$ intervals, correlated to the sympathetic control sinus node by the autonomic nervous system (Mourot et al., 2004).

Some works have discussed the analysis of HRV variables for understanding the physiological and biological phenomena occurring during physical training (Mourot et al., 2004) in patients with congestive heart failure (Y. Isler, 2007) and during the practice of meditation (A. Goshvarpour, 2011).

\section{Statistical Analysis}

The data were evaluated using analysis of variance (ANOVA) upon comparison of the mean values of variables in different sets. It was assumed an alpha error of $5 \%$, with $p$-values less than or equal to 0.05 being considered significant. For cases where the $p$ value by ANOVA was 0.05 or less then it was applied the multiple comparison test of Tukey pairwise comparisons (Driscoll, 1996). Finally for comparison in terms of predictive validity related
Table 1: Example of the contigency table or confusion matrix to classify models by ROC analysis.

\begin{tabular}{l|ll|l} 
& $\mathrm{P}$ & $\mathrm{N}$ & Total \\
\hline Yes & TP & FP & TP+FP \\
No & FN & TN & FN+VN \\
\hline Total & TP+FN & FP+TN & TP+FP+FN+VN
\end{tabular}

$\mathrm{TP}=$ true positive - number of ill patients classified by test; FP = false positive - number of non-diseased not classifed by test; $\mathrm{FN}=$ false negative - number of ill patients not classified by test; $\mathrm{TN}=$ true negative - number of nondiseased classified correctly by test.

to the extension of the time series considered, the ROC curve analysis was used.

The analysis by the Receiver Operating Characteristic Curve (ROC) is a technical classification largely used in signal detection theory to represent the exchange between the success rates and rates of false classification given by a particular variable and can be used to assess the applicability of diagnostic methods (Fawcett, 2006). Initially, according to (Fawcett, 2006), consider the classification problem using two classes. Each case $i$ is mapped to an element of the set of positive class (P) (possessing a certain characteristic, for example, being sick) or negative $(\mathrm{N})$ (not possessing a certain characteristic, for example, not being sick). To distinguish the current class from the predictive class, the labels yes (the characteristic follows a certain established cutoff point) and no (the characteristic does not have a certain cutoff point) are used for the classes predicted by the model (see Table 1).

From Table 1 some information may be obtained, (i) the sensitivity $(\mathrm{S}=\mathrm{TP} /(\mathrm{TP}+\mathrm{FN}))$, which is defined as the probability of a test to give a positive result, given that the patient has the disease or condition, (ii) specificity $(\mathrm{Sp}=\mathrm{TN} /(\mathrm{TN}+\mathrm{FP}))$, defined as the probability of a negative result, given that the patient does not have the disease or the desired trait, (iii) the positive predictive value $(\mathrm{PPV}=\mathrm{TP} /(\mathrm{TP}+\mathrm{FP}))$, defined as the percentage of patients having the disease or condition given that the test results are positive, (iv) the negative predictive value $(\mathrm{NPV}=\mathrm{TN} /(\mathrm{TN}+\mathrm{FN}))$, the percentage of patients not having the disease or condition given that the test results are indeed negative, and positive likelihood ratio (LRP $=$ sensitivity $/(1$ - specificity)) which corresponds to the ratio between the probability of a diagnostic test to be positive on someone having the disease (sensitivity) and the probability of that test to be positive in those without the disease (1-specific features).

\section{Results}

Comparisons of tachograms collected with the Polar monitor (S810i and S800) were performed using three sets with series of different extensions: 


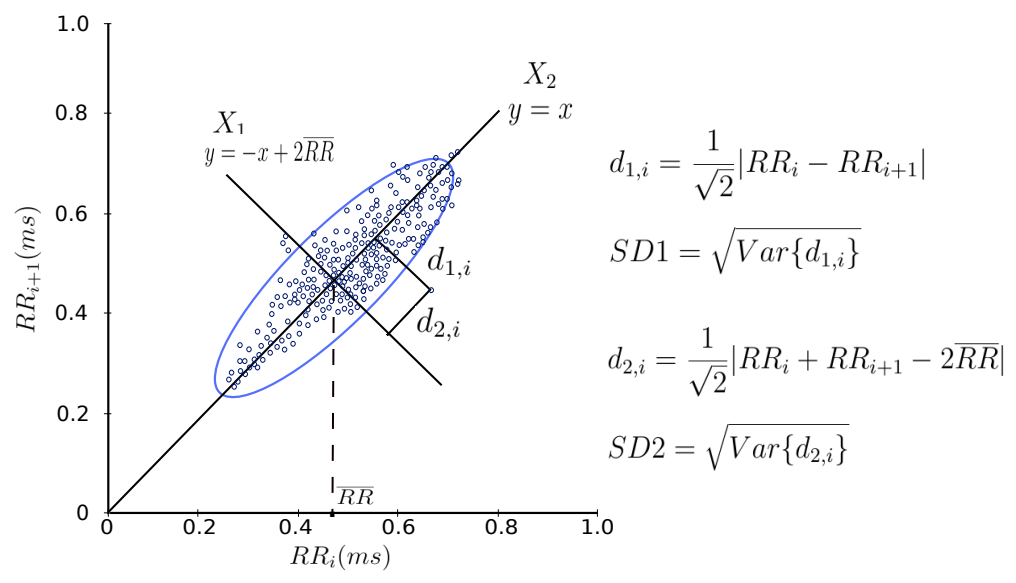

Figure 1: Example of Poincaré plot obtained from a tachogram. The parameters extracted from the graph are: $X 2$ (line identity), $X 1$ (perpendicular to the line identity), centroid (intersection between the means of $x$-axis $\left(R R_{1}, R R_{2}, \ldots, R R_{n}\right)$ and the $y$-axis $\left(R R_{2}, R R_{3}, \ldots, R R_{N+1}\right), S D 1$ (standard deviation over $X 1$ ) related to short-term HRV, $S D 2$ (standard deviation over $X 2$ ) related to long-term HRV and $S D 1 / S D 2$ (ratio of short and long range variations).

$1,000,2,000$ and the total number of intervals collected (between 2,000 and 3,000). The purpose was to found the minimum number of RR intervals required for the analysis to maintain correspondence with the total sizes of tachogram $(\geq 2,000$ $\mathrm{RR}$ intervals). Initially, all sets of total sizes were filtered to remove artifacts using the adaptive filtering method. This filtering method removes the intervals with values below $350 \mathrm{~ms}$ and above $1,200 \mathrm{~ms}$. The intervals are filtered as described in (Wessel et al., 2000). After filtering, the series were divided into the desired sizes and separately had the parameters $S D 1, S D 2$ and $S D 1 / S D 2$ calculated from the Poincaré plot.

To verify the ability of these variables associated with different sizes for the prediction of events, the clinical interpretation of the groups was taken into account. From a clinical standpoint of 42 patients submitted to revascularization surgery and who had assessment of heart rate variability prior to the operation five died postsurgery and 37 were discharged from hospital.

For this analysis the same series (same patient) was considered in three different sizes: $1,000,2,000$ and total $\mathrm{RR}$ intervals (between 2,000 and 3,000) with $p \geq 0.05$, that is, the averages are not significantly different from each other. The objective was to verify if this scenario with the series with 1000-RR interval-long series were equivalent to the interpretation obtained from the total series of RR intervals and if the parameters of the Poincaré plot could be used as predictors of death in this group of patients.

To determine the effectiveness of the diagnostic test, ROC curve analysis was used by setting values of the matrix of confusion (or contingency table) for each variable analyzed.

Table 2 shows an example of the confusion matrix for the parameter $S D 1$ designed for full-
Table 2: Confusion matrix for the parameter $S D 1$ considering the total size of the RR interval series of 42 patients undergoing preoperative coronary artery bypass.

\begin{tabular}{l|ll|l}
$S D 1-$ size total & death & not death & Total \\
\hline patients positive results* & 5 & 18 & 23 \\
patients negative results** & 0 & 19 & 19 \\
\hline Total & 5 & 37 & 42
\end{tabular}

* $S D 1 \leq 11.65$ (cutoff point)

$* * S D 1>11.65$

sized series of 42 patients in the pre-operative with a cutoff value of 11.65 .

The ROC curve was assessed in this context to examine the performance of diagnosis (prediction) studying the sensitivity and specificity of the Poincaré plot parameters given a particular cutoff value. Table 3 shows the cutoff values, sensitivity $(\mathrm{S})$, specificity $(\mathrm{Sp})$, positive likelihood ratio (LRP), accuracy (A) and area under the ROC curve of the Poincaré plot parameters considering different sizes of the series of RR intervals of 42 patients. This set was divided in two groups: one that includes the presence of the event analyzed ( 5 died after surgery) and the second group without including the event analyzed (37 recovered after surgery).

Upon considering the parameters of the Poincaré plot, the different sizes of the tachograms analyzed yielded sensitivity and specificity values very similar to each other, with an area under the ROC curve above 0.60 demonstrating that the length of the series (from 1,000 intervals to more than 2,000 is irrelevant for the predictive capacity), with relatively high levels of accuracy (A), in general.

Figure 2 shows the ROC curves obtained from analysis of the chart parameter $S D 1$ Poincaré con- 
Table 3: ROC analysis of Poincaré plot parameters considering three different sizes of the RR intervals time series $(1,000,2,000$ and total). It is possible to see that, independently of the size of the time series values of sensitivity $(\mathrm{S})$, specificity $(\mathrm{Sp})$, obtained are the similar to each other.

\begin{tabular}{|c|c|c|c|c|c|c|c|}
\hline Parameter & Size & Cutoff & $\mathrm{S}$ & $\mathrm{Sp}$ & $\mathrm{A}$ & LRP & Area under ROC curve \\
\hline \multirow{3}{*}{$S D 1$} & total & 11.65 & 1 & 0.51 & 0.57 & 2.06 & $0.75(0.46$ to 1$)$ \\
\hline & 1000 & 12.13 & 1 & 0.51 & 0.57 & 2.06 & $0.76(0.47$ to 1$)$ \\
\hline & 2000 & 11.63 & 1 & 0.51 & 0.57 & 2.06 & $0.75(0.46$ to 1$)$ \\
\hline \multirow{3}{*}{$S D 2$} & total & 36.17 & 0.8 & 0.57 & 0.60 & 1.85 & $0.61(0.30$ to 0.92$)$ \\
\hline & 1000 & 45.48 & 1 & 0.46 & 0.52 & 1.85 & $0.67(0.37$ to 0.97$)$ \\
\hline & 2000 & 36.55 & 0.8 & 0.57 & 0.60 & 1.85 & $0.64(0.34$ to 0.95$)$ \\
\hline \multirow{3}{*}{$S D 1 / S D 2$} & total & 0.20 & 0.6 & 0.81 & 0.79 & 3.17 & $0.61(0.30$ to 0.91$)$ \\
\hline & 1000 & 0.21 & 0.6 & 0.84 & 0.81 & 3.70 & $0.66(0.36$ to 0.96$)$ \\
\hline & 2000 & 0.20 & 0.6 & 0.81 & 0.79 & 3.17 & $0.62(0.31$ to 0.92$)$ \\
\hline
\end{tabular}

sidering the different sizes of tachogram analyzed. It is noted that Figures $2 \mathrm{~A}, 2 \mathrm{~B}$ and $2 \mathrm{C}$ all have an area under the ROC curve very similar, confirming that this parameter showed a good performance in predicting death in the event the data set analyzed.

\section{Conclusion}

For prediction of adverse events (in the present context, the death of a patient), the Poincaré plot parameters were analyzed for 42 time series (acquired with the Polar) with different extensions captured from adults with severe coronary disease in the preoperative evaluation for coronary artery bypass grafting.

The results indicated that the series from 1,000 to over $2,000 \mathrm{RR}$ intervals preserved its ability to predict death in the postoperative period of surgical myocardial revascularization (using $S D 1, S D 2$ or $S D 1 / S D 2$ as predictors).

\section{Acknowlegments}

The authors thank the Coordination for the Improvement of Higher Level Personnel (CAPES/Brazil) for financial support, the graduate students, researchers and NUTECC group members who participated over the last years of systematic collection of time series, especially Isabela Thomaz Takakura and Paulo Rogério Corrêa.

\section{References}

A. Goshvarpour, A. Goshvarpour, S. R. (2011). Analysis of lagged Poincaré plots in heart rate signals during meditation, Digital Signal Processing 21: 208-214. DOI: 10.1016/j.dsp.2010.06.015

Brennan, M., Palaniswami, M. and Kamen, P. (2001). Do existing measures of Poincaré plot geometry reflect nonlinear features of heart rate variability?, IEEE Transactions on Biomedical Engineering 48(11): 1342-1347. DOI: $10.1109 / 10.959330$

Driscoll, W. C. (1996). Robustness of the ANOVA and Tukey-Kramer statistical tests, Comput-ers \& Industrial Engineering 31: 265-268. DOI: 10.1016/0360-8352(96)00127-1

Fawcett, T. (2006). An introduction to ROC analysis, Pattern Recognition Letters 2006: 861874. DOI: $10.1016 /$ j.patrec.2005.10.010

Gamelin, F. X., Berthoin, S. and Bosquet, L. (2006). Validity of the polar S810 heart rate monitor to measure $\mathrm{RR}$ intervals at rest, Medicine \& Science in Sports \& Exercised 38(5): 887-893. DOI: 10.1249/01.mss.0000218135.79476.9c

Goldsmith, R. L., Bigger, J. T., Bloomfield, D. M., Krum, H., Steinman, R. C., SacknerBernstein, J. and Packer, M. (1997). Longterm carvedilol therapy increases parasympathetic nervous system activity in chronic congestive heart failure, The American Journal of Cardiology 80: 1101-1104. DOI: 10.1016/S0002-9149(97)00616-4

Karmakar, C. K., Khandoker, A. H., Gubbi, J. and Palaniswami, M. (2009). Complex correlation measure: a novel descriptor for Poincaré plot, BioMedical Engineering Online $\mathbf{8}(17)$.

Krum, H., Jr, J. T. B., Goldsmith, R. L. and Packer, M. (1995). Effect of long-term digoxin therapy on autonomic function in patients with chronic heart failure, Journal of the American College of Cardiology 25: 289294. DOI: 10.1016/0735-1097(94)00417-O

Mourot, L., Bouhaddi, M., Perrey, S., Rouillon, J. D. and Regnard, J. (2004). Quantitative Poincaré plot analysis of heart rate variability: effect of endurance training, European Journal of Applied Physiology 91: 79-87. DOI: 10.1007/s00421-003-0917-0

Nunan, D., Donovan, G., Jakovljevic, D. G., Hodges, L. D., Sandercock, G. R. and Brodie, 
(a)

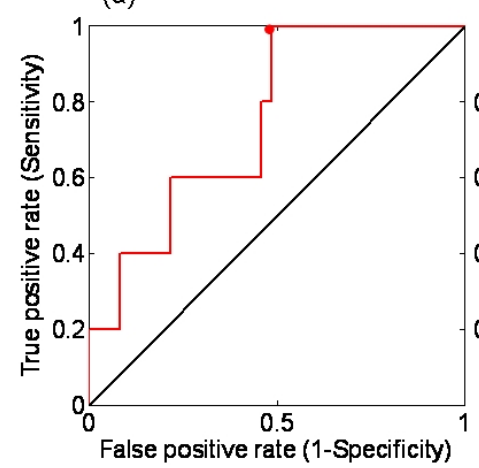

(b)

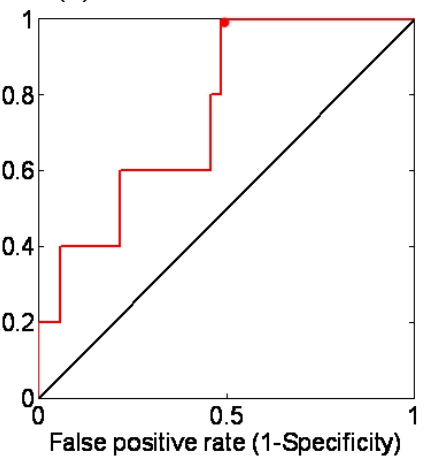

(c)

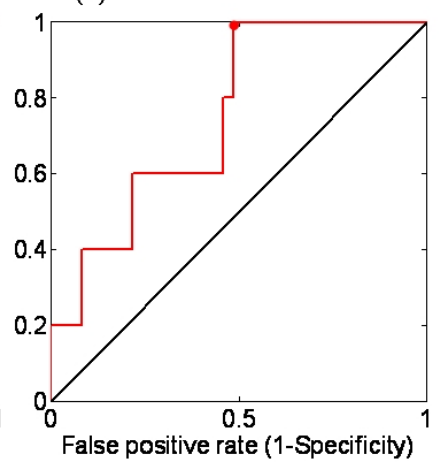

Figure 2: ROC curve from $S D 1$ parameter. (a) RR intervals total, cutoff $\leq 11.65$ (o); (b) series with $1000 \mathrm{RR}$ intervals, cutoff $\leq 12.13$ (o) and (c) series with $2000 \mathrm{RR}$ intervals, cutoff $\leq 11.63$ (o).

D. A. (2009). Validity and reliability of shortterm heart-rate variability from the polar S810, Med Sci Sports Exerc 41(1): 243-250. DOI: $10.1249 / \mathrm{MSS} .0 \mathrm{~b} 013 \mathrm{e} 318184 \mathrm{a} 4 \mathrm{~b} 1$

Piskorski, J. and Guzik, P. (2007). Geometry of the Poincaré plot of rr intervals and its asymmetry in healthy adults, Physiological Mea-surement 28: 287-300. DOI: $10.1088 / 0967-3334 / 28 / 3 / 005$

Selig, F. A., Tonolli, E. R., da Silva, E. V. C. M. and de Godoy, M. F. (2011). Variabilidade da frequencia cardiaca em neonatos prematuros e de termo, Arq. Bras. Cardiol. 96(6): 443449. DOI: 10.1590/S0066-782X2011005000059

Vanderlei, L. C., Pastre, C. M., Hoshi, R. A., Carvalho, T. D. and Godoy, M. F. (2009). Noções básicas de variabilidade da frequência cardiaca e sua aplicabilidade clínica., Braz J Med Biol Res 24(2).

Vanderlei, L. C., Silva, R. A., Pastre, C. M., Azevedo, F. M. and Godoy, M. F. (2008). Comparison of the polar S810i monitor and the ECG for the analysis of heart rate variability in the time and frequency domains, Braz J Med Biol Res 41(10): 854-859. DOI: 10.1590/S0100-879X2008005000039

Wessel, N., Malberg, H., Ziehmann, C., Voss, H. U., Schirdewan, A., Meyerfeldt, U. and Kurths, J. (2000). Nonlinear analysis of complex phenomena in cardiological data, Herzschr Elektrophys 11: 159-173.

Y. Isler, M. K. (2007). Combining classical HRV indices with wavelet entropy measures improves to performance in diagnosing congestive heart failure, Computers in Biology and Medicine 37: $1502-1510 . \quad$ DOI: 10.1016/j.compbiomed.2007.01.012 